\title{
Lipid-lowering effects of methanolic extract of Vernonia amygdalina leaves in rats fed on high cholesterol diet
}

\author{
Oluwatosin A Adaramoye \\ Olajumoke Akintayo \\ Jonah Achem \\ Michael A Fafunso \\ Department of Biochemistry, Faculty \\ of Basic Medical Sciences, College of \\ Medicine, University of Ibadan, Ibadan, \\ Nigeria
}

\begin{abstract}
We investigated the lipid-lowering effects of methanolic extract of Vernonia amygdalina (VA) leaves in rats fed an high cholesterol diet, and compared with a standard hypolipidemic drug, Questran $(\mathrm{Qu})$. The effects of VA on the lipid profile were assessed by measuring the levels of total cholesterol, triglyceride, low-density lipoprotein (LDL) cholesterol, high-density lipoprotein (HDL) cholesterol, lipid peroxidation (LPO), phospholipid, and glutathione (GSH) in the plasma and liver of the rats. Administration of cholesterol at a dose of $30 \mathrm{mg} / 0.3 \mathrm{ml}$, five times in a week for nine consecutive weeks resulted in a significant increase $(\mathrm{p}<0.05)$ in plasma and post mitochondrial fraction (PMF) cholesterol levels by $33 \%$ and 55\%, respectively. However, treatment with extract of VA at doses of 100 and $200 \mathrm{mg} / \mathrm{kg}$ caused a dose dependent reduction in the plasma and PMF cholesterol by $20 \%, 23 \%$ and $23 \%, 29 \%$, respectively. Similar reduction in cholesterol levels was obtained in Qu-treated rats. Furthermore, VA at $200 \mathrm{mg} / \mathrm{kg}$ decreased the plasma and PMF LDL-cholesterol levels by $23 \%$ and $49 \%$, and also decreased plasma and PMF triglyceride levels by $29 \%$ and $28 \%$, respectively. Also, VA at 100 and $200 \mathrm{mg} / \mathrm{kg}$ caused a dosedependent increase in plasma HDL-cholesterol levels by $41 \%$ and $59 \%$, respectively. However, there were no significant differences $(p>0.05)$ in the PMF HDL-cholesterol and phospholipid levels of the treated rats when compared to hypercholesterolemic rats. There were significant decreases $(p<0.05)$ in the LPO levels of extract-treated rats. Precisely, VA at 100 and 200 $\mathrm{mg} / \mathrm{kg}$ decreased the levels of plasma and PMF LPO by 38\%, 42\% and 35\%, 45\%, respectively. In addition, VA augmented the cholesterol-induced decrease in PMF glutathione levels of the rats. Taken together, these results suggest the lipid-lowering effects of VA and, probably serve as a new potential natural product for the treatment of hyperlipidemia.
\end{abstract}

Keywords: hypercholesterolemia, lipid-lowering effect, Vernonia amygdalina, cholesterol

\section{Introduction}

It is known that hypercholesterolemia is a risk factor for cardiovascular diseases (CVD) such as atherosclerosis and myocardial infarction, which is a common cause of mortality and morbidity (Wald and Law 1995; Krieger 1998). Although several factors, such as life style, a diet rich in cholesterol, age and hypertension, have been reported to cause heart failure (Schaefer et al 1995), high levels of cholesterol, particularly LDL cholesterol, are mainly responsible for hypercholesterolemia (Krieger 1998). Recently, hypercholesterolemia has been associated with enhanced oxidative stress related to increase lipid peroxidation (Adaramoye et al 2005). Increased generation of oxidized LDL is a major factor in the vascular damage associated with high cholesterol levels (Pritchard et al 1995). Hence, the inhibition of oxidative stress under hypercholesterolemic conditions is considered to be an important therapeutic approach and efforts have been made to identify the antioxidative functions of various medicinal plants $(\mathrm{Hu}$ et al 2006; Tomotake et al 2006; Visavadiya and Narasimhacharya 2007). 
Drugs that lower cholesterol such as fibrates and bile acid sequestrants were used for several decades, but the high prevalence of their adverse effects led to the introduction of statins (HMG CoA inhibitors) (Miller 2001). Although the adverse effect of statins is relatively low, one rare effect called rhabdomyolysis can be very serious (Miller 2001). This effect is very pronounced when a statin is taken with another type of cholesterol lowering drug, in particular fibrates (Miller 2001). Rhabdomyolysis led to the voluntary withdrawal of cerivastatin (Baycol) by its manufacturer. In view of the adverse effects associated with synthetic lipid-lowering drugs, the quest for natural products with lipid-lowering potential and with minimal or no side effect is warranted.

Plants have been the companions of man since time immemorial and formed the basis of useful drugs since they are less toxic than synthetic drugs. Screening of medicinal plants presents an avenue for the discovery of new drugs. Vernonia amygdalina (VA) is a shrub that grows predominantly in the tropical Africa. Leaves from this plant serve as food vegetable and culinary herb in soup (Argheore et al 1998). In Nigerian herbal homes, extracts of the plant are used as tonic, in the control of tick and treatment of cough, feverish condition, constipation and hypertension (Regassa 2000; Kambizi and Afolayan 2001; Amira and Okubadejo 2007). Phytochemical screening of VA revealed the presence of saponins, sesquiterpene, and flavonoids (Igile et al 1994). Strong antioxidant activities have been reported for flavonoids from VA and, its saponins have been reported to elicit antitumoral activities in leukemia cells (Jisaka et al 1993). Peptides from VA are known to be potent inhibitor of mitogen-activated proteins kinases, which are crucial for breast tumor growth and also represents a key regulatory point for the tumour (Izevbigie 2003; Izevbigie and Ernest 2005). However, there is dearth of scientific data to support the folkloric use of this plant in the treatment of hypertension or related vascular diseases in Nigerian herbal homes. Therefore, the present work was designed to provide scientific proof of the use of VA in the treatment of vascular diseases.

\section{Methods}

\section{Chemicals}

Cholesterol and thiobarbituric acid (TBA) were procured from Aldrich Chemical Co. (Milwaukee, WI, USA). Questran (Bristol-Myers Squibb, Hounslow, UK) was purchased from a local chemist in Ibadan, Nigeria. Diagnostic kits for cholesterol and triglyceride were procured from Boehringer Mannheim GmbH Diagnostica, Germany. Other reagents were of analytical grade and the purest quality available.

\section{Preparation of plant extract}

Fresh leaves of Vernonia amygdalina were obtained from a local market, Sasa in Ibadan, Nigeria. The botanical identification and authentication was confirmed at the Department of Botany, University of Ibadan, Nigeria, where voucher specimen was kept at the herbarium (Voucher no. UI-02567). The leaves were air-dried at room temperature and then powdered. The powdered sample $(1 \mathrm{~kg})$ was defatted with n-hexane (2.5 litres) and then extracted with $75 \%$ methanol (2.5 litres) overnight in a soxhlet extractor (Sri Rudran Instrument Co, Chennai, India). The methanolic extract was concentrated and evaporated to dryness at $50^{\circ} \mathrm{C}$ with a rotary evaporator under reduced pressure, and the yield of the preparation was $6.8 \%$. The extract was dissolved in water at a concentration of $4 \mathrm{~g} / 100 \mathrm{ml}$, and aliquots of different concentrations were given orally to the animals with a gavage needle.

\section{Grouping of animals and study design}

Forty-two male albino rats (Wistar strain) weighing between $120-130 \mathrm{~g}$ were used as experimental animals. The rats were kept in cages in a room maintained at $26-29{ }^{\circ} \mathrm{C}$ with a 12-hour light-dark cycle for 4-weeks to acclimatize, and were allowed free access to food and water ad libitum. The protocol conforms to the guidelines of the National Institute of Health (NIH) (NIH publication 85-23, 1985) for laboratory animal care and use. Animals were randomly distributed into seven groups of six animals each. Group A served as control (received drug-vehicle, water), rats in groups $\mathrm{B}$ and $\mathrm{C}$ were administered VA at doses 100 and $200 \mathrm{mg} / \mathrm{kg}$ body weight, respectively in addition to oral administration of cholesterol. Rats in group D were intubated with cholesterol-only (hypercholesterolemic animals). Rats in group E served as positive control and were given VA at a dose of $100 \mathrm{mg} / \mathrm{kg}$ body weight, while rats in group $\mathrm{F}$ were intubated with cholesterol and Questran. Rats in group G were treated orally with Questran-only. Cholesterol was orally administered at a dose of $30 \mathrm{mg} / 0.3 \mathrm{ml} /$ animal, while Questran was given at a therapeutic dose of $0.26 \mathrm{~g} / \mathrm{kg}$ body weight (Adaramoye et al 2005). Extract of VA was administered at doses 100 and $200 \mathrm{mg} / \mathrm{kg}$ body weight (Iwalokun et al 2006). VA, Questran, and cholesterol were administered five times in a week for a period of nine weeks.

\section{Sample collection}

After the last dose of drugs, rats were fasted overnight and sacrificed by cervical dislocation. Blood was collected from the heart into EDTA tubes. Plasma was prepared 
by centrifugation at 3,000 $\mathrm{g}$ for 15 minutes in an MSC bench centrifuge (Beckman and Hirsch, Burlington, IO, USA). The plasma was used in the estimation of lipid profile. Liver from the animals were rinsed in ice- cold $1.15 \% \mathrm{KCl}$, dried and weighed. It was homogenized in 4 volumes of ice-cold $5 \mathrm{mM}$ phosphate buffer, $\mathrm{pH} 7.4$, and centrifuged at 10,000 $\mathrm{g}$ for $20 \mathrm{~min}$ to obtain post mitochondrial fraction (PMF). Organs such as kidneys, lungs, liver and heart were removed from the animals and weighed.

\section{Determination of triglyceride and cholesterol levels}

Triglyceride and cholesterol levels were assayed using Boehringer Mannheim diagnostic kits.

\section{Determination of protein and phospholipid levels}

Protein level was determined by the method of Lowry and colleagues (1951). Briefly, the method involved the reduction of phospho-18 molybdic tungstic complex by phenolic groups present in amino acids to blue precipitate at alkaline $\mathrm{pH}$. The precipitate was read spectrophotometrically at $720 \mathrm{~nm}$. The level of phospholipid was assayed by the method of Fiske and SubbaRow (1925). The method involves the release of inorganic phosphate from phospholipid in presence of an acceptor in aqueous medium. The inorganic phosphate reacts with ammonium molybdate and ascorbate to form a blue precipitate which was read at $660 \mathrm{~nm}$ spectrophotometrically.

\section{Determination of HDL and LDL cholesterol levels}

The lipoproteins, VLDL and LDL were precipitated using phosphotungstic acid and magnesium chloride. After centrifugation, the supernatant contained the HDL fraction, which was assayed for cholesterol with diagnostic kit. LDL cholesterol was calculated using the formula of Friedewald and colleagues (1972).
Determination of lipid peroxidation (LPO) and reduced glutathione (GSH) levels

Lipid peroxidation and reduced glutathione levels were assayed by the methods of Walls and colleagues (1976) and Moron and colleagues (1979), respectively. Briefly, GSH level was assayed by measuring the rate of formation of chromphoric product in a reaction between DTNB $\left(5,5^{1}-\right.$ dinitro bis (2-nitrobenzoic acid) and free sulphydryl groups (such as GSH) at $412 \mathrm{~nm}$, while the extent of LPO was estimated by the measuring the intensity of pink precipitate formed in a reaction between malondialdehyde (MDA, end-product of lipid peroxidation) and thiobarbituric acid at $535 \mathrm{~nm}$ spectrophotometrically.

\section{Statistical analysis}

Results were expressed as the mean \pm S.D. $(n=6)$. A oneway analysis of variance (ANOVA) was used for the data analysis, using SPSS (Statistical Package for Social Sciences) (10.0) software. Significant differences between groups were detected in the ANOVA using Duncan's Multiple Range Test at $p$ values less than 0.05 and 0.001 .

\section{Results}

Table 1 depicts the effect of Vernonia amygdalina on body weight, organs weight and relative weight of visceral organs of hypercholesterolemic rats. Extract of VA at 100 and $200 \mathrm{mg} / \mathrm{kg}$ did not affect the body weight gain during this study. However, there was a significant increase $(p<0.001)$ in the body weight gain of hypercholesterolemic rats when compared with the control. In Table 2 , there were significant $(\mathrm{p}<0.001)$ increases in the plasma HDL cholesterol levels of animals treated with VA when compared with the hypercholesterolemic rats. Furthermore, administration of cholesterol caused a significant increase $(\mathrm{p}<0.05)$ in the plasma and PMF total cholesterol

Table I Effect of Vernonia amygdalina on body weight, organ weight, and relative weight of visceral organs of hypercholesterolemic rats

\begin{tabular}{|c|c|c|c|c|c|c|c|c|c|}
\hline \multirow[t]{2}{*}{ Grouping } & \multicolumn{2}{|c|}{ Body weight (g) } & \multirow[b]{2}{*}{ Change } & \multirow[t]{2}{*}{$\begin{array}{l}\text { Lungs } \\
\text { (g) }\end{array}$} & \multirow[t]{2}{*}{$\begin{array}{l}\text { Kidneys } \\
\text { (g) }\end{array}$} & \multirow[t]{2}{*}{$\begin{array}{l}\text { Heart } \\
(\mathrm{g})\end{array}$} & \multirow[t]{2}{*}{$\begin{array}{l}\text { Liver } \\
\text { (g) }\end{array}$} & \multicolumn{2}{|c|}{$\begin{array}{l}\text { Relative weight } \\
\text { (\% body weight) }\end{array}$} \\
\hline & Initial & Final & & & & & & Heart & Liver \\
\hline CONTROL & $125.0 \pm 5.2$ & $171.0 \pm 7.6$ & $46.0 \pm 8.6$ & $1.6 \pm 0.1$ & $1.6 \pm 0.1$ & $0.80 \pm 0.1$ & $6.1 \pm 0.5$ & $0.47 \pm 0.1$ & $3.6 \pm 0.4$ \\
\hline $\mathrm{VAI}+\mathrm{CH}$ & $120.2 \pm 4.7$ & $168.3 \pm 5.7$ & $48.1 \pm 11.3$ & $1.5 \pm 0.4$ & $1.5 \pm 0.1$ & $0.75 \pm 0.1$ & $5.8 \pm 0.8$ & $0.47 \pm 0.1$ & $3.7 \pm 0.5$ \\
\hline $\mathrm{VA} 2+\mathrm{CH}$ & $130.0 \pm 4.5$ & $174.0 \pm 6.1$ & $44.0 \pm 5.5$ & $1.6 \pm 0.3$ & $1.5 \pm 0.3$ & $0.82 \pm 0.2$ & $6.0 \pm 0.6$ & $0.47 \pm 0.1$ & $3.5 \pm 0.3$ \\
\hline CH ONLY & $120.0 \pm 3.0$ & $178.3 \pm 6.0$ & $58.3 \pm 6.0^{*}$ & $1.7 \pm 0.3$ & $1.8 \pm 0.2$ & $0.86 \pm 0.2$ & $6.2 \pm 0.3$ & $0.48 \pm 0.1$ & $3.5 \pm 0.4$ \\
\hline VAI ONLY & $120.3 \pm 3.5$ & $166.6 \pm 4.3$ & $46.3 \pm 8.3$ & $1.6 \pm 0.3$ & $1.8 \pm 0.5$ & $0.80 \pm 0.2$ & $6.1 \pm 0.7$ & $0.48 \pm 0.0$ & $3.7 \pm 0.4$ \\
\hline $\mathrm{QU}+\mathrm{CH}$ & $125.0 \pm 4.3$ & $170.0 \pm 7.9$ & $45.0 \pm 7.2$ & $1.5 \pm 0.1$ & $1.6 \pm 0.2$ & $0.82 \pm 0.1$ & $5.9 \pm 0.5$ & $0.48 \pm 0.1$ & $3.5 \pm 0.5$ \\
\hline QU ONLY & $130.0 \pm 5.8$ & $176.0 \pm 8.7$ & $46.0 \pm 8.8$ & $1.7 \pm 0.2$ & $1.7 \pm 0.4$ & $0.79 \pm 0.1$ & $6.0 \pm 0.6$ & $0.45 \pm 0.1$ & $3.4 \pm 0.5$ \\
\hline
\end{tabular}

Notes: Values are means \pm S.D. of six animals; *Significantly different at $p<0.00 \mathrm{I}$ from others.

Abbreviations: VA, Vernonia amygdalina; CH, cholesterol; QU, Questran; VAI, 100 mg/kg;VA2, 200 mg/kg. 
Table 2 Effect of Vernonia amygdalina on protein, phospholipid, high-density lipoprotein (HDL), and low-density lipoprotein (LDL) cholesterol levels of hypercholesterolemic rats

\begin{tabular}{|c|c|c|c|c|c|c|}
\hline \multirow[t]{2}{*}{ Grouping } & \multicolumn{2}{|c|}{ Protein content } & \multirow{2}{*}{$\begin{array}{l}\text { Phospholipid } \\
\text { PMF } \\
\text { (mg/dL) }\end{array}$} & \multicolumn{2}{|c|}{ HDL-cholesterol } & \multirow{2}{*}{$\begin{array}{l}\text { LDL-cholesterol } \\
\text { PMF } \\
\text { (mmol/g liver) }\end{array}$} \\
\hline & $\begin{array}{l}\text { Plasma } \\
(\mathrm{g} / \mathrm{ml})\end{array}$ & $\begin{array}{l}\text { PMF } \\
\text { (mg/g liver) }\end{array}$ & & $\begin{array}{l}\text { Plasma } \\
(\mathrm{mmol} / \mathrm{L})\end{array}$ & $\begin{array}{l}\text { PMF } \\
\text { (mmol/g liver) }\end{array}$ & \\
\hline CONTROL & $7.0 \pm 1.3$ & $2.4 \pm 0.3$ & $542.8 \pm 13.6$ & $0.28 \pm 0.07^{*}$ & $0.09 \pm 0.02$ & $2.9 \pm 0.9 * *$ \\
\hline $\mathrm{VAI}+\mathrm{CH}$ & $6.8 \pm 1.4$ & $2.8 \pm 0.8$ & $532.5 \pm 10.3$ & $0.24 \pm 0.04 *$ & $0.10 \pm 0.02$ & $4.8 \pm 1.2$ \\
\hline $\mathrm{VA} 2+\mathrm{CH}$ & $6.5 \pm 1.8$ & $2.1 \pm 0.6$ & $535.7 \pm 16.7$ & $0.27 \pm 0.06 *$ & $0.10 \pm 0.02$ & $3.2 \pm 1.2 * *$ \\
\hline $\mathrm{CH} O \mathrm{ONLY}$ & $6.1 \pm 1.5$ & $2.4 \pm 0.3$ & $545.2 \pm 11.4$ & $0.17 \pm 0.03$ & $0.09 \pm 0.02$ & $6.2 \pm 0.8$ \\
\hline VAI ONLY & $6.2 \pm 0.6$ & $2.5 \pm 0.5$ & $548.6 \pm 11.9$ & $0.28 \pm 0.05^{*}$ & $0.09 \pm 0.01$ & $2.6 \pm 0.8 * *$ \\
\hline $\mathrm{QU}+\mathrm{CH}$ & $6.5 \pm 1.4$ & $2.6 \pm 1.5$ & $547.8 \pm 14.6$ & $0.19 \pm 0.05$ & $0.08 \pm 0.02$ & $5.0 \pm 1.4$ \\
\hline QU ONLY & $6.0 \pm 0.5$ & $2.5 \pm 0.5$ & $536.5 \pm 13.8$ & $0.26 \pm 0.05^{*}$ & $0.09 \pm 0.01$ & $3.2 \pm 0.9 * *$ \\
\hline
\end{tabular}

Notes: Values are means \pm S.D. of six animals; $*$ Significantly different from $\mathrm{CH}$ group at $\mathrm{p}<0.00$ I; **Significantly different from $\mathrm{CH}$ group at $\mathrm{p}<0.05$.

Abbreviations: VA, Vernonia amygdalina; CH, cholesterol; QU, Questran; PMF, post mitochondrial fraction; VAI, 100 mg/kg;VA2, 200 mg/kg.

and triglyceride levels of the rats (Figures 1 and 2). Precisely, plasma and PMF levels of total cholesterol and triglyceride were increased by $33 \%, 55 \%$ and $44 \%, 80 \%$, respectively. The hypercholesterolemia induced by the dietary cholesterol was significantly attenuated $(\mathrm{p}<0.05)$ in animals treated with VA and Questran. Furthermore, VA at a dose of $200 \mathrm{mg} / \mathrm{kg}$ was able to decrease the hypertriglyceridemia induced by dietary cholesterol (Figure 2). Administration of dietary cholesterol significantly $(\mathrm{p}<0.05)$ increased plasma and PMF LPO by $58 \%$ and $90 \%$, respectively (Figure 3 ). However, the cholesterol-induced increase in plasma and PMF LPO was significantly $(p<0.05)$ attenuated by extract of VA. Specifically, VA at 100 and $200 \mathrm{mg} / \mathrm{kg}$ decreased the plasma and PMF LPO by $38 \%, 42 \%$ and $35 \%, 45 \%$, respectively. Table 2 and
Figure 4 show that cholesterol administration significantly $(p<0.05)$ elevated the plasma and PMF LDL cholesterol levels of hypercholesterolemic rats. Specifically, plasma and PMF LDL cholesterol levels were elevated by $41 \%$ and $115 \%$, respectively. However, VA at $200 \mathrm{mg} / \mathrm{kg}$ significantly attenuated $(\mathrm{p}<0.05)$ the cholesterol-induced increase in plasma and PMF LDL cholesterol by $23 \%$ and $49 \%$, respectively. Similarly, the cholesterol-induced decrease in PMF reduced glutathione levels of hypercholesterolemic rats were significantly $(\mathrm{p}<0.05)$ ameliorated in animals treated with VA (Figure 4).

\section{Discussion}

The presence of a high amount of cholesterol in the diet has been demonstrated to elevate plasma cholesterol and

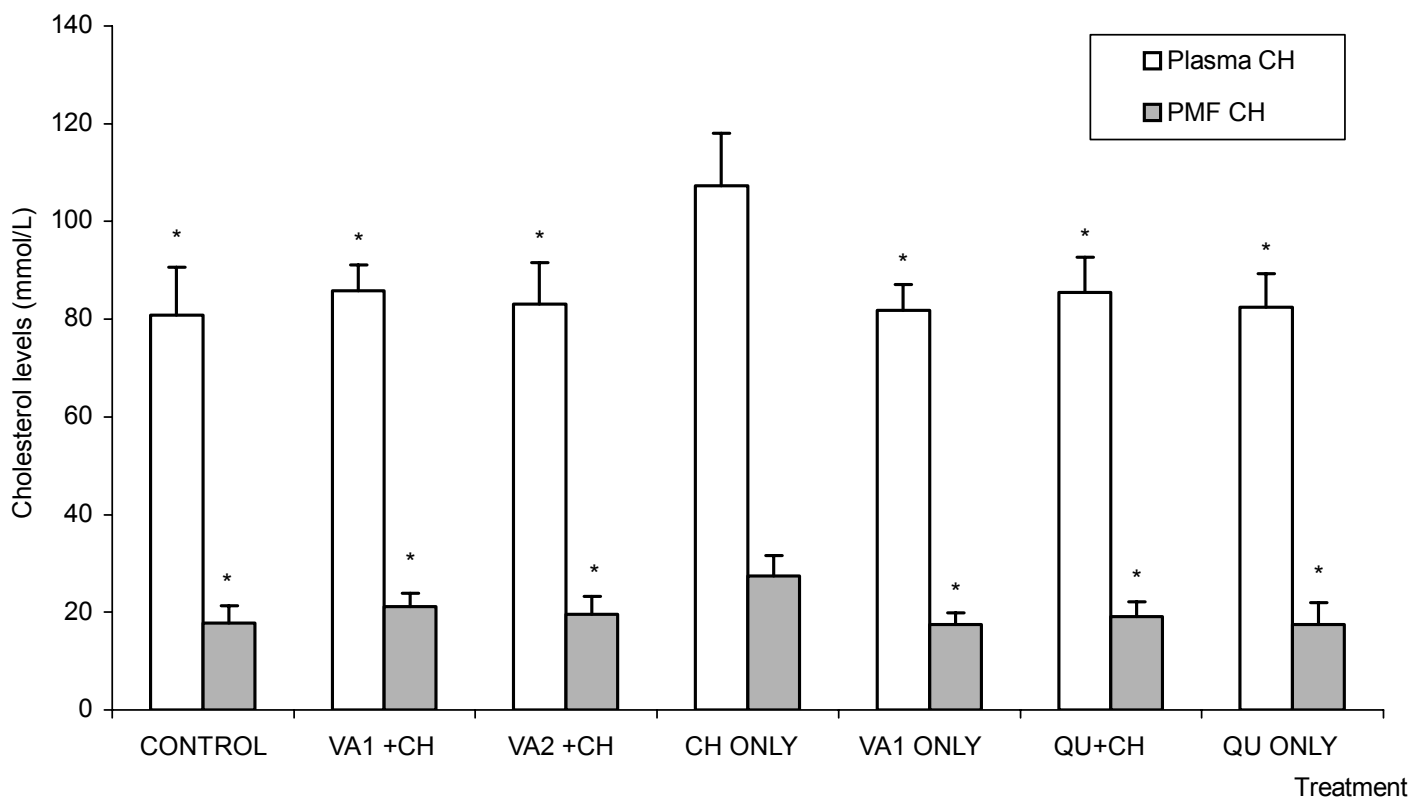

Figure I Effect of Vernonia amygdalina on plasma and post mitochondrial fraction (PMF) cholesterol levels of hypercholesterolemic rats. Note: *Significantly different from $\mathrm{CH}$ group at $\mathrm{p}<0.05$.

Abbreviations: $\mathrm{CH}$, Cholesterol; VA,Vernonia amygdalina; QU, Questran; PMF, Post mitochondrial fraction; VAI, 100 mg/kg; VA2, 200 mg/kg. 


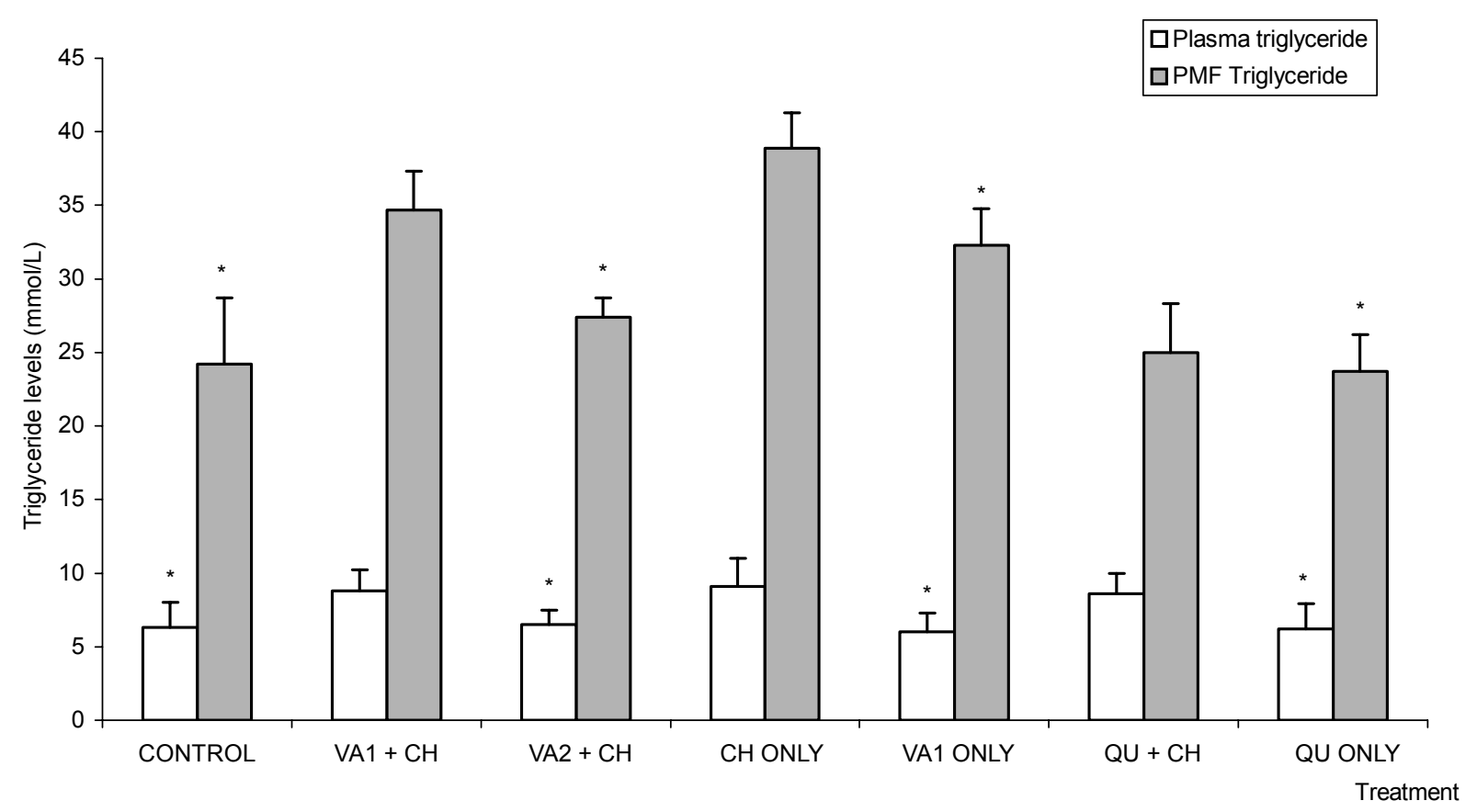

Figure 2 Effect of Vernonia amygdalina on plasma and post mitochondrial fraction (PMF) triglyceride levels of hypercholesterolemic rats. Note: *Significantly different from $\mathrm{CH}$ group at $\mathrm{p}<0.05$.

Abbreviations: $\mathrm{CH}$, Cholesterol; VA, Vernonia amygdalina; QU, Questran; PMF, Post mitochondrial fraction; VAI, 100 mg/kg;VA2, 200 mg/kg.

may increase aortic atherosclerosis (LRCP 1984). Several studies have indicated that diet treatment or drug therapy to regulate cholesterol can reduce subsequent CVD-associated mortality and morbidity (Kwiterovich 1997). On the basis of this, great efforts have been made to reduce the risk of CVD through the regulation of cholesterol, thus the therapeutic benefits of plant foods have been the focus of many extensive dietary studies (Yokozawa et al 2006; Zhang et al 2007).

In the present study, we investigated the lipid-lowering effects of Vernonia amygdalina in rats fed on high cholesterol diet for a period of nine weeks. Notably, the rats

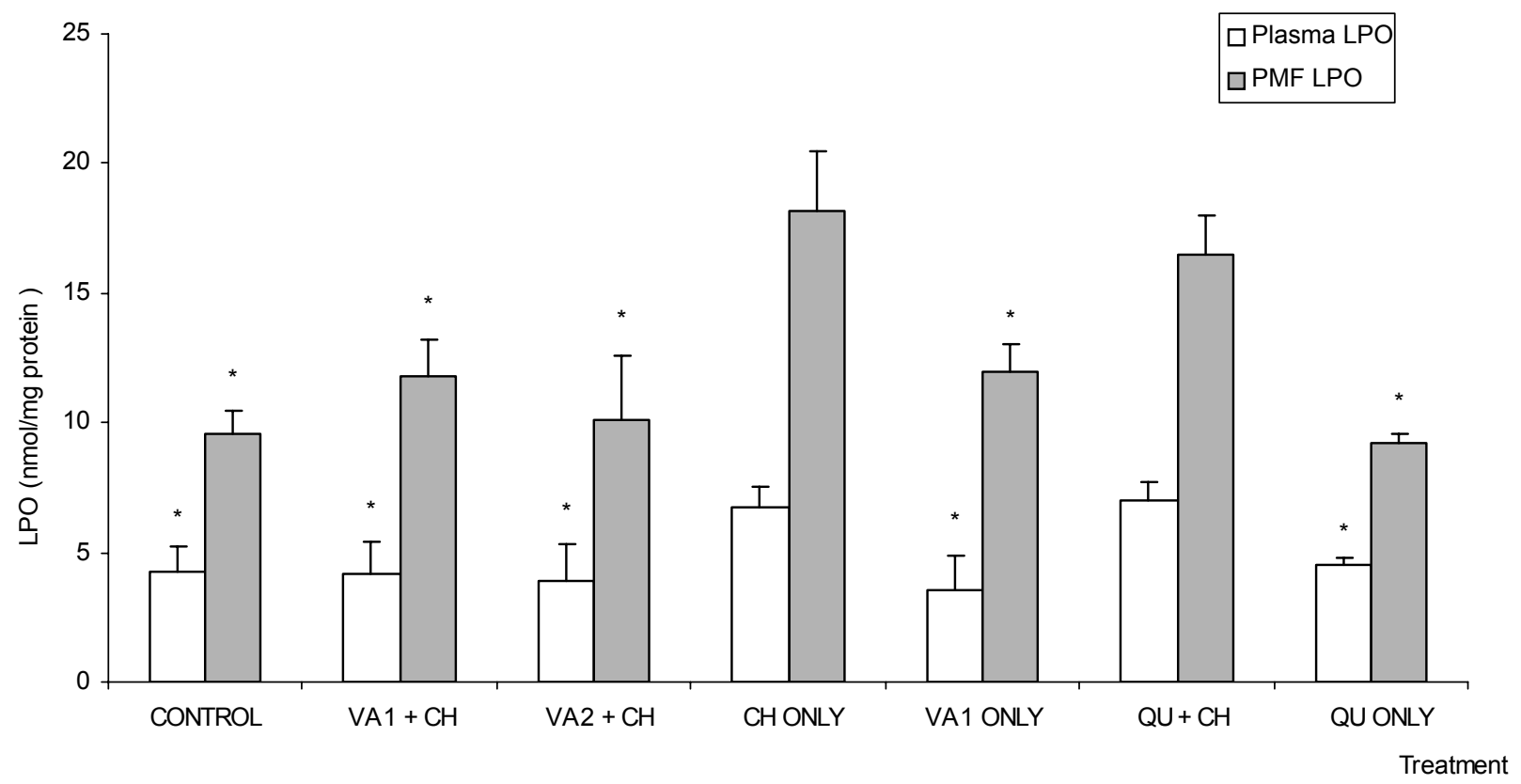

Figure 3 Effect of Vernonia amygdalina on plasma and post mitochondrial fraction (PMF) lipid peroxidation levels of hypercholesterolemic rats.

Note: *Significantly different from $\mathrm{CH}$ group at $\mathrm{p}<0.05$.

Abbreviations: CH, Cholesterol;VA, Vernonia amygdalina; QU, Questran; LPO, Lipid peroxidation; VAI, 100 mg/kg;VA2, 200 mg/kg. 


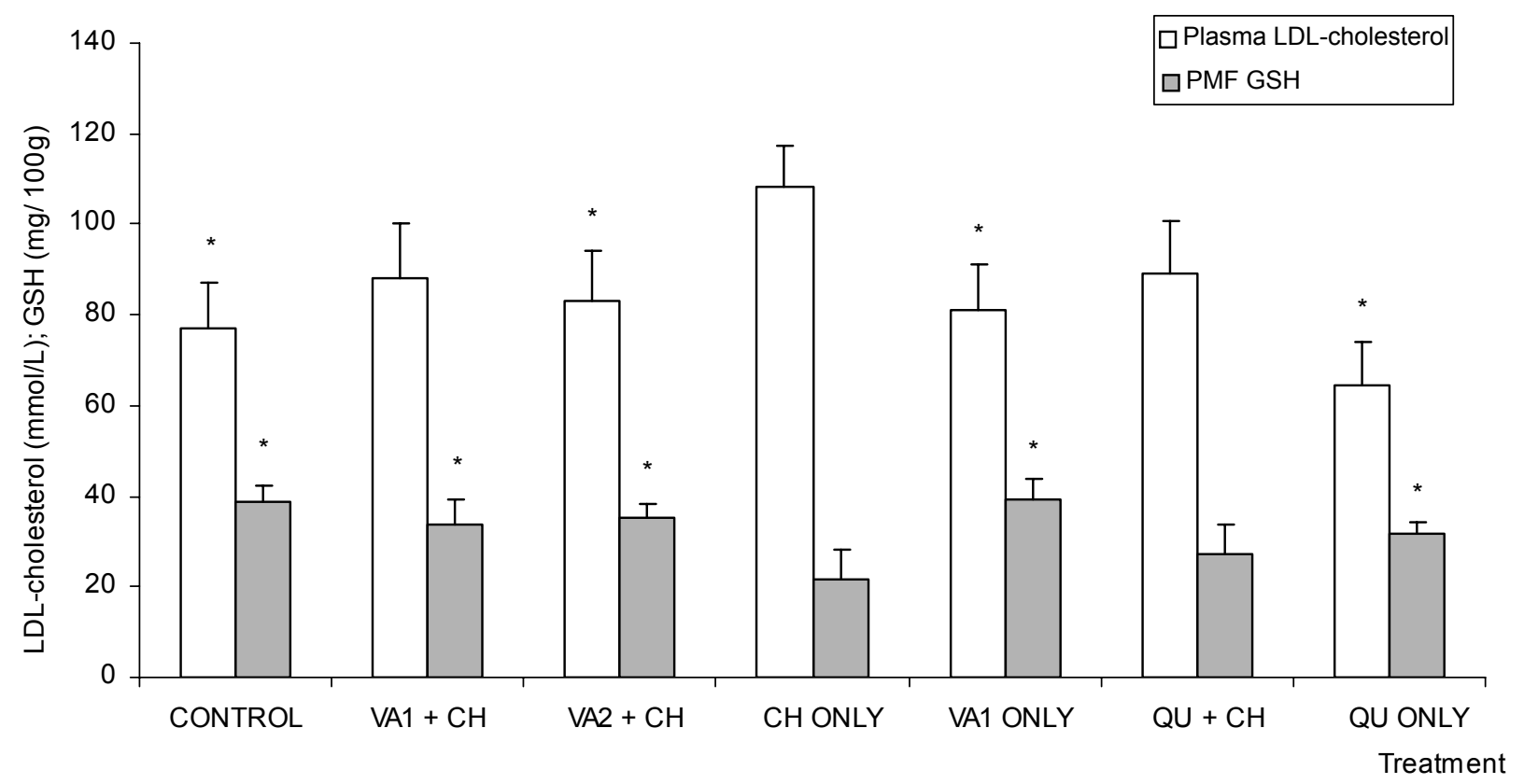

Figure 4 Effect of Vernonia amygdalina on plasma LDL-cholesterol and post mitochondrial fraction (PMF) reduced glutathione levels of hypercholesterolemic rats. Note: *Significantly different from $\mathrm{CH}$ group at $\mathrm{p}<0.05$.

Abbreviations: $\mathrm{CH}$, Cholesterol; VA, Vernonia amygdalina; QU, Questran; LDL, Low-density lipoprotein; PMF, Post mitochondrial fraction; GSH, Reduced glutathione; VAI, $100 \mathrm{mg} / \mathrm{kg}$; VA2, $200 \mathrm{mg} / \mathrm{kg}$.

intubated with dietary cholesterol showed higher plasma and hepatic levels of total cholesterol and triglyceride than the extract-treated animals. It is obvious that the reducing effect produced by Vernonia amygdalina on plasma and PMF cholesterol levels is dose dependent. Dietary cholesterol has been shown to reduce fatty acid oxidation, which, in turn, increases the levels of hepatic and plasma triglycerol (Fungwe et al 1993). The elevated levels of plasma and PMF triglyceride obtained in cholesterol-fed rats are in line with the findings of Adaramoye and colleagues (2005) and Yokozawa and colleagues (2006). The results suggest that VA $(200 \mathrm{mg} / \mathrm{kg}$ ) reduced the hepatic triglyceride biosynthesis and favour the redistribution of cholesterol among the lipoprotein molecules. This observation is consistent with the findings of Nwanjo (2005) in which VA significantly attenuated the hepatic triglyceride and LDL cholesterol levels of streptozotocin diabetic rats.

The crucial risk factor for CVD includes a low level of HDL-cholesterol. The association between a low level of HDL-cholesterol and an increased risk of CVD has been well established through epidemiological and clinical studies (Assmann and Gotto 2004). Since low level of HDLcholesterol plays a direct role in the atherogenic process, therapeutic intervention to raise HDL-cholesterol together with other risk factors is widely encouraged. In this study, treatment with VA led to significant elevation of plasma HDL-cholesterol, indicating its promising protective role against CVD. The protective roles of HDL cholesterol from CVD have been suggested to occur in various ways (Nofer et al 2002). HDL exerts part of its anti-atherogenic effect by counteracting LDL oxidation and, recent studies also showed that HDL promotes the reverse cholesterol transport pathway, by inducing an efflux of excess accumulated cellular cholesterol and prevents the generation of an oxidatively modified LDL (Yokozawa et al 2006). Furthermore, HDL inhibits the oxidation of LDL by transition metal ions, but also prevents 12-lipooxygenase-mediated formation of lipid hydroperoxides (Nofer et al 2002). On the basis of our results, VA may probably plays an anti-atherogenic role through the inhibition of lipids oxidation, (due to its anti-lipoperoxidative effect observed in this study) as well as the elevation of HDL cholesterol.

LDL cholesterol is another primary target of CVD riskreduction therapy (Kwiterovich 1997). In this study, VA administered at a dose of $200 \mathrm{mg} / \mathrm{kg}$ lowered LDL cholesterol levels of hypercholesterolemic rats. Excess LDL can be deposited in the blood vessel walls and becomes a major component of atherosclerotic plaque lesions. Therefore, plasma LDL cholesterol level may be used for monitoring the treatment of patients with elevated blood cholesterol levels. In view of our results, VA elicited beneficial effects by lowering the plasma and PMF levels of cholesterol including low-density lipoprotein of the treated rats. Oxidative stress, defined as a disruption of the balance between oxidative 
and antioxidative processes, plays an important role in the pathogenesis of atherosclerosis (Yokozawa et al 2006). A cholesterol rich diet results in increased lipid peroxidation, followed by hypercholesterolemia (Adaramoye et al 2005). The relationship between oxidative stress and cholesterol level was confirmed in the present study, in which the hepatic glutathione (GSH), an indicator of antioxidant defense, exhibited a negative correlation with the hepatic total cholesterol levels of hypercholesterolemic rats, but a positive correlation with the cholesterol levels of extractpretreated rats. Therefore, VA may elicit some health benefits through the modulation of physiologic functions including the atherogenic lipid profile.

Evidence from this study confirms the lipid-lowering effects of VA in rats fed on high cholesterol diet. VA at $200 \mathrm{mg} / \mathrm{kg}$ was effective in reducing the levels of plasma and PMF total cholesterol as well as low-density lipoprotein cholesterol. Further studies are warranted to determine the exact component in VA responsible for the observed effect and, such component may be a candidate for use as a prophylactic agent against hypercholesterolemia.

\section{References}

Adaramoye OA, Nwaneri VO, Anyanwu KC, et al. 2005. Possible antiatherogenic effect of kolaviron (a Garcinia kola seed extract) in hypercholesterolemic rats. Clin Exp Pharmacol Physiol, 32:40-6.

Amira CA, Okubadejo NU. 2007. Frequency of complementary and alternative medicine utilization in hypertensive patients attending an urban tertiary care centres in Nigeria. BMC Complementary and Alternative Medicine, 7:30-48.

Argheore EM, Makkar HPS, Becker K. 1998. Feed value of some browse plants from central zone of Delta State of Nigeria. Trop Sci, 38:97-104.

Assmann G, Gotto AM Jr. 2004. HDL cholesterol and protective factors in atherosclerosis. Circulation, 109:III8-III14.

Fiske CH, SubbaRow Y. 1925. The colorimetric determination of phosphorus. J Biol Chem, 66:375-83.

Friedewald WT, Levy RI, Fredrickson DS. et al. 1972. Estimation of the concentration of LDL cholesterol in plasma, without use of the preparative ultra- centrifuge. Clin Chem, 18:499-502.

Fungwe TV, Cagen LM, Cook GA, et al. 1993. Dietary cholesterol stimulated hepatic biosynthesis of triglyceride and reduces oxidation of fatty acids in the rat. J Lipid Res, 34:933-41.

Hu SH, Liang ZC, Chia YC, et al. 2006. Antihyperlipidemic and antioxidant effects of extracts from Pleurotus citrinopileatus. J Agric Food Chem, 22:2103-10.

Igile GO, Oleszek W, Jurzysta M, et al. 1994. Flavonoids from Vernonia amygdalina and their antioxidant activities. J Agric Food Chem, 42:2445-8.

Iwalokun BA, Efedede BU, Alabi-Sofunde JA, et al. 2006. Hepatoprotective and antioxidant activities of Vernonia amygdalina on acetaminopheninduced hepatic damage in mice. J Med Food, 9:524-30.

Izevbigie EB. 2003. Discovery of water-soluble anticancer agents (edotides) from a vegetable found in Benin City, Nigeria. Exp Biol Med, 228:293-8.

Izevbigie EB, Ernest O. 2005. Phytochemotherapy for cancer. US Patent No $6,849,604$.

Jisaka M, Ohigashi H, Takagawa K, et al. 1993. Steroid glucosides from Vernonia amygdalina. A possible Chimpanzee medicinal plant. Phytochemistry, 34:409-13.
Kambizi L, Afolayan AJ. 2001. An ethnobotanical study of plants used for the treatment of sexually transmitted diseases (njovhera) in Guruve District, Zimbabwe. J Ethnopharmacol, 77:5-9.

Krieger M. 1998. The "best" of cholesterols, the "worst" of cholesterols: a tale of two receptors. Proc Natl Acad Sci USA, 95:4077-80.

Kwiterovich PO Jr. 1997. The effect of dietary fat, antioxidants, and prooxidants on blood lipids, lipoproteins, and atherosclerosis. J Am Diet Assoc, 97:S31-41.

Lowry OH, Rosenbrough NJ, Farr AL, et al. 1951. Protein measurement with Folin-phenol reagent. J Biol Chem, 193:265-75.

Lipid Research Clinics Program. 1984. The lipid research clinics, coronary primary prevention trial results 1 . Reduction in incidence of coronary heart disease. J Am Med Assoc, 251:351-64.

Miller CA. 2001. Update on statins and other lipid-lowering drugs. Geriatr Nurs, 22:276-77.

Moron MA, Depierre JW, Mannervick B. 1979. Levels of glutathione, glutathione reductase and glutathions-S-transferase activities in rat lung and liver. Biochem Biophys Acta, 582:67-78.

Nwanjo HU. 2005. Efficacy of aqueous leaf extract of Vernonia amygdalina on plasma lipoprotein and oxidative status in diabetic rat models. Niger J Physiol Sci, 20:39-42.

Nofer JR, Kehrel B, Fobker M, et al. 2002. HDL and arteriosclerosis: beyond reverse cholesterol transport. Atherosclerosis, 161:1-16.

Pritchard KA Jr, Groszek L, Smalley DM, et al. 1995. Native low-density lipoprotein increases endothelial cell nitric oxide synthase generation of superoxide anion. Circ Res, 77:510-18.

Regassa A. 2000. The use of herbal preparation for tick control in Western Ethiopia. J S Afr Vet Assoc, 71:240-3.

Schaefer EJ, Lichtenstein AH, Lamon-Fava S, et al. 1995. Lipoproteins, nutrition, aging and atherosclerosis. Am J Clin Nutri, 61:726S-740S.

Tomotake H, Yamamoto N, Yanaka N, et al. 2006. High protein buckwheat flour suppresses hypercholesterolemia in rats and gallstone formation in mice by hypercholesterolemic diet and body fat in rats because of its low protein digestibility. Nutr, 22:166-73.

Visavadiya NP, Narasimhacharya AV. 2007. Ameliorative effect of Chlorophytum borivilianum root on lipid metabolism in hyperlipaemic rats. Clin Exp Pharmacol Physiol, 34:244-9.

Wald NJ, Law MR. 1995. Serum cholesterol and ischaemic heart disease. Atherosclerosis, 118:1-5.

Walls R, Kumar KS, Hochstein P. 1976. Ageing of human erythrocytes. Arch Biochem Biophys, 100:119-28.

Yokozawa T, Cho EJ, Sasaki S, et al. 2006. The protective role of Chinese prescription Kangen-karyu extract on diet-induced hypercholesterolemia in rats. Biol Pharm Bull, 29:760-5.

Zhang HW, Zhang YH, Lu MJ, et al. 2007. Comparison of hypertension, dyslipidaemia and hyperglycaemia between buckwheat seed-consuming and non-consuming mongolian-chinese populations in inner mongolia, China. Clin Exp Pharmacol Physiol, 34:838-44. 
